\title{
Maintenance cimetidine instead of surgery for duodenal ulcer: the first decade
}

\author{
D T HANSELL, $M$ McGUSHIN, $R$ N MEDDINGS, I S SMITH, G R GRAY, \\ AND G GILLESPIE
}

From the Department of Surgery, Victoria Infirmary, Glasgow

\begin{abstract}
SUMmary Fifty five patients with severe longstanding dyspepsia originally selected as candidates for elective duodenal ulcer surgery were instead entered into a maintenance cimetidine study. Forty six have been reviewed after 10 years. Twenty patients had required surgery, all in the first three years, but six of them had proven or suspected recurrent ulceration during follow up. Twenty six patients avoided surgery, either with continuous cimetidine $400 \mathrm{mg}$ nocte or intermittent full dose cimetidine. Of the 17 on continuous maintenance cimetidine, six had proven or suspected recurrent ulceration responding to full dose cimetidine. All nine patients on intermittent cimetidine experienced symptomatic relapse within eight to 12 weeks of drug withdrawal. By using cimetidine, $64 \%$ of patients selected for surgery have avoided operation over this 10 year period, although none has had drug free remission.
\end{abstract}

During 1976 and 1977, 55 patients with longstanding chronic duodenal ulceration, who had been accepted for elective surgery on the indication of failed medical therapy, consented to receive maintenance treatment with cimetidine rather than undergo surgery. In the event of failure of maintenance therapy, either as assessed by the patient or by the medical staff, elective surgery remained available. These patients had participated in a double blind one year maintenance study, the results of which have been published previously.' A review of this patient group was published at five years.

\section{Methods}

PATIENTS

The 55 patients ( 44 men) commenced maintenance with $400 \mathrm{mg}$ cimetidine at bedtime immediately after an endoscopy which had shown complete healing of their duodenal ulcers. Healing had been achieved either by full dose cimetidine therapy ( $1 \mathrm{~g} /$ day) or by spontaneous remission. During the first year of maintenance, endoscopy was repeated at the six month stage but earlier if ulcer symptoms had returned. Thereafter therapy was prescribed and

Address for correspondence: D T Hansell, Department of Surgery, Victoria Infirmary, Glasgow G42 9TY, Scotland.

Accepted for publication 7 November 1988. controlled by the general practitioners, who were made fully aware of the management plan for these patients. Most patients were reviewed at the surgical outpatient clinic every four to six months and, specifically for the purposes of the study, all patients were reviewed at the end of one, five, and 10 years. At this last review, clinical assessment and endoscopy were performed on all surviving patients. Assessment was carried out by a clinician not involved in the earlier management of these patients. Any patient who had died during the follow up period, whether or not operated upon, was classified according to their latest review.

At entry into the study, the mean age of the patients was $45 \cdot 2$ years $(2 \cdot 3)$ SEM and the mean duration of ulcer symptoms was 12.5 years $(1.7)$ SEM. Two thirds of them smoked more than 15 cigarettes per day. During their earlier ulcer history, 13 patients had experienced episodes of gastrointestinal haemorrhage requiring transfusion, while nine had required simple closure of a perforated duodenal ulcer.

\section{Results}

From the original 55 patients, four were lost to follow up by the five year stage and a further five were lost from the 10 year review. Of the remaining 46 
patients, 20 had required surgery (surgery group) at varying intervals after starting maintenance cimetidine, while 26 were receiving cimetidine (cimetidine group).

\section{SURGERY GROUP}

\section{Indication}

The reasons for and timing of surgery in the 20 patients are shown in the Figure. All patients requiring surgery did so within three years of commencing maintenance cimetidine.

\section{Pyloric stenosis}

The five patients who underwent surgery for pyloric stenosis all had clinical and radiological evidence of pyloric channel obstruction, manifested as stasis vomiting.

\section{Haemorrhage}

The two patients who required surgery for haemorrhage had been admitted as emergencies with hypotension, frank haematemesis and/or melaena. These patients rebled within 48-72 hours from endoscopically confirmed duodenal ulcers, and required transfusion of five and seven pints of whole blood respectively in the pre- and perioperative period.

\section{Pain}

Eight patients underwent surgery as a result of

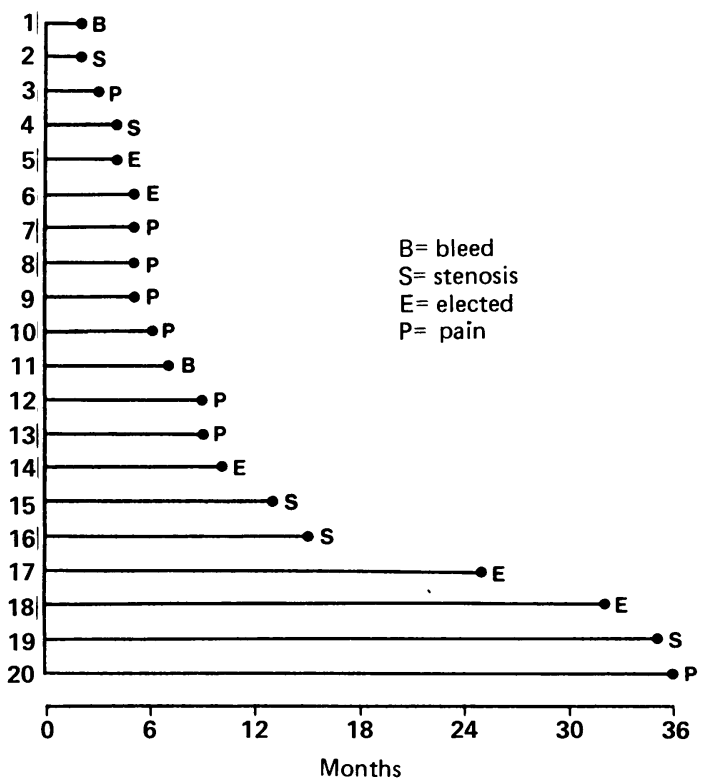

Figure Timing and reasons for surgery in the 20 duodenal ulcer patients who required operation. frequent recurrence of dyspeptic symptoms of a magnitude similar to that which led them to be referred as candidates for surgery before starting maintenance cimetidine. They were all shown endoscopically to have recurrent ulceration not responding to therapeutic doses of cimetidine ( $1 \mathrm{~g} /$ day $)$ over a four week period.

\section{Elect}

Five patients 'elected' to have surgery for recurrence of dyspepsia. While these patients had experienced improvement on cimetidine and showed no evidence of ulceration at endoscopy, they felt dissatisfied at incomplete symptom relief and exercised an option to have surgery as had been agreed at entry into the study.

\section{MAXIMAL ACID OUTPUT}

Ten of the 20 patients requiring surgery underwent preoperative maximal acid output (MAO) to pentagastrin testing. Five had MAOs in excess of 45 $\mathrm{mmol} / \mathrm{h}$ (two patients with bleeding, two with pain, one with stenosis).

\section{OPERATION}

In 17 of these patients a truncal vagotomy with pyloroplasty or gastrojejunostomy was performed, but in three patients with gastric hypersecretion (MAO to pentagastrin $>45 \mathrm{mmol} / \mathrm{h}$ ) a truncal vagotomy and antrectomy was performed at the discretion of the surgeon. There were no immediate postoperative deaths.

\section{RECURRENT ULCERATION AFTER SURGERY}

During the 10 year follow up six patients developed symptoms of recurrent ulceration. Four of these were proven endoscopically to have a recurrent duodenal or stomal ulcer. The other two, who had entered

Table Details of patients who died during follow up (19771987)

\begin{tabular}{|c|c|c|c|c|}
\hline Patient & $\begin{array}{l}\text { Age at } \\
\text { death }\end{array}$ & $\begin{array}{l}\text { Year of } \\
\text { death }\end{array}$ & $\begin{array}{l}\text { Cigarettes/ } \\
\text { day }\end{array}$ & Cause of death \\
\hline \multicolumn{5}{|c|}{ Surgery group: } \\
\hline ED & 43 & 1979 & 15 & Drug overdose (hypnotics) \\
\hline JH & 73 & 1982 & 10 & Myocardial infarction \\
\hline MG & 40 & 1984 & 15 & Conn's syndrome \\
\hline $\mathrm{CF}$ & 53 & 1985 & 15 & Bronchial carcinoma \\
\hline \multicolumn{5}{|c|}{ Cimetidine group: } \\
\hline WB & 69 & 1977 & 20 & Ruptured aortic aneurysm \\
\hline WB & 63 & 1979 & 20 & Bronchial carcinoma \\
\hline $\mathrm{FL}$ & 60 & 1980 & 15 & Myocardial infarction \\
\hline $\mathrm{JP}$ & 44 & 1984 & 15 & Myocardial infarction \\
\hline $\mathrm{AH}$ & 63 & 1986 & 15 & Bronchial carcinoma \\
\hline DR & 35 & 1987 & 30 & $\begin{array}{l}\text { Bleeding oesophageal varices } \\
\text { (+ischaemic heart disease) }\end{array}$ \\
\hline
\end{tabular}


symptomatic remission when seen, had no endoscopic evidence of ulceration, having already been started on cimetidine by their general practitioner. Recurrent ulcer after vagotomy and drainage was managed in all patients with full dose cimetidine therapy to obtain healing, then reducing to a maintenance dosage. In two of these patients known to have preoperative $\mathrm{MAOs}>45 \mathrm{mmol} / \mathrm{h}$, however, control was obtained with this regimen in the short term only. In the long term, one required antrectomy because of poor symptom control while the other was not available for longterm assessment, having died during the follow up period (ED - Table).

ASYM PTOMATIC

The remaining 14 patients had no symptoms of recurrent ulceration during the follow up period, but three of them had died of unrelated causes (Table).

\section{CIMETIDINE GROUP}

At the 10 year stage all 26 patients who had avoided surgery continued to use cimetidine in one of two ways: (a) Seventeen patients took nightly maintenance cimetidine $400 \mathrm{mg}$ virtually continuously. Most of them had attempted to withdraw their maintenance on one or more occasions in the earlier years but all had experienced a return of ulcer symptoms within eight to 12 weeks and therefore returned to their maintenance dose to control symptoms. Five of these patients died during follow up but none had experienced a return of dyspepsia (Table). The 12 surviving patients all claimed to be well and none had ulceration at endoscopy at the 10 year review.

At some stage during the 10 year follow up, however, six of these patients had experienced symptoms suggestive of recurrent ulceration despite maintenance therapy. Three of them had proved to have endoscopic ulcers but the other three patients, who had entered remission by the time of their endoscopy, had no endoscopic evidence of ulceration. All six, however, had responded to an increased cimetidine dosage of $400 \mathrm{mg}$ bd for four weeks. (b) Nine patients continued to use cimetidine on an intermittent basis. During the periods when they attempted to do without cimetidine all relapsed symptomatically within eight to 12 weeks. These symptoms were controlled by full dose cimetidine $(800-1000 \mathrm{mg} / \mathrm{day})$, either self administered or as prescribed by the general practitioner. None of these patients, therefore, could be regarded as 'ulcer free', yet at the 10 year review only two of the nine patients were symptomatic, both having endoscopic ulceration. A further patient (DR - Table) died about the time of the 10 year review before endoscopy could be performed. Postmortem examination revealed no active ulcer.

\section{SIDE EFFECTS}

No significant side effects have been noted during this 10 year experience of cimetidine therapy. One patient developed bilateral calf cramps which eased on stopping the drug. He chose to treat himself with intermittent courses of cimetidine, but later required surgery for bleeding ulcer.

\section{DEATHS (Table)}

Ten of the 46 patients died during the 10 year follow up. Their mean age at death was 54.3 years. None of the deaths could be attributed to peptic ulceration. Smoking related diseases predominated, and no patient alive or dead had a gastric malignancy.

\section{Discussion}

Two questions were asked at the outset of these studies: first, to what extent could patients at the severe end of the ulcer spectrum be managed conservatively, and second, could the natural history of the duodenal ulcer diathesis be altered by longterm $\mathrm{H}_{2}$ blockade?

This study was not a randomised trial to compare $\mathrm{H}_{2}$ receptor antagonists with elective duodenal ulcer surgery. It was rather an attempt to explore the premise that longterm $\mathrm{H}_{2}$ receptor blockade might avoid elective duodenal ulcer surgery. In the event, 20 of the 55 patients $(36 \%)$ did require operation as for them the use of cimetidine maintenance proved unsatisfactory. From the timing of surgery it is clear that failure of maintenance tended to occur early in the follow up period, with 16 of the 20 patients having surgery within the first 15 months of attempted maintenance. At the time of operation, 10 of the 20 patients had an active ulcer (eight with pain, two with bleeding) while five of the remainder had developed pyloric stenosis. The remaining five had felt that they would rather not continue with 'lifetime' maintenance. They, therefore, had exercised their option to have surgery on return of symptoms. The high incidence of pyloric stenosis may reflect the effect of accelerated healing of substantial ulceration by cimetidine, as none of these patients had had evidence of pyloroduodenal channel narrowing at the time of entry into the study. ${ }^{2}$

The 10 patients with active ulceration, although not having 'refractory ulcers' as defined by Bardhan, ${ }^{3}$ might be suspected of being at the more severe end of the ulcer spectrum. Thus, they may be more likely to develop recurrent ulceration after a standard vagotomy and drainage. The occurrence of six (35\%) recurrent ulcers, either suspected or proven, in the 17 patients who had a truncal vagotomy and drainage is certainly higher than would be expected. It is noteworthy that a recent report has observed a $34 \%$ 
recurrence rate at five years after highly selective vagotomy for 'refractory ulcer'. ${ }^{4}$

Five patients who came to surgery were found to have preoperative MAOs in excess of $45 \mathrm{mmol} / \mathrm{h}$ and none of the three who underwent truncal vagotomy with antrectomy developed recurrent ulceration. The other two with hypersecretion did develop early recurrence after truncal vagotomy and drainage and in the long term one required antrectomy.

The fact that no patient required surgery after three years of maintenance treatment is noteworthy. Indeed, of the 20 patients who had an operation, 16 of them had surgery within 18 months of commencing maintenance cimetidine. This could suggest that those patients requiring surgery were at the more severe end of the duodenal ulcer spectrum. The possibility that it may also reflect a greater confidence in longterm medical therapy on the part of the clinician as the study progressed is thought unlikely, as no patient developed uncontrolled haemorrhage or pyloric obstruction requiring emergency surgery.

Regular night time maintenance cimetidine therapy suppresses overnight acid secretion but allows the gastric $\mathrm{pH}$ to return to highly acidic values by day. This form of dosing should avoid the potential hazards of longterm acid suppression which theoretically could result in the build up of nitrosamines and other potentially carcinogenic substances. None of the deaths in this report was the result of peptic ulceration or gastric malignancy.

It should be noted that in the first year of this study two of the 55 patients bled and required surgery, a finding which compares closely with the recent outpatient study of maintenance in general practice in Clydebank ${ }^{5}$ where five of 150 patients on continuous maintenance either bled or perforated. Breakthrough symptoms had occurred occasionally in six of the group on longterm nightly maintenance but all responded promptly to a temporary increase in dosage either on the patient's initiative or on the advice of the general practitioner. The correlation between the presence of active ulcer symptoms and endoscopic ulceration was excellent. Compliance may be difficult to assess in a longterm outpatient study, but almost all the patients on continuous maintenance did admit at visits to the outpatient clinic to attempting to withdraw their therapy on at least one occasion. This was followed invariably by a return of their symptoms necessitating a return to their maintenance therapy, so that by the later years of the review most patients still taking cimetidine had learned to do so continuously.

Although 35 patients avoided surgery, follow up would appear to have been complete in only 26
(74\%). The problem posed by defaulters in allowing accurate assessment of longterm treatment has recently been highlighted, ${ }^{\circ}$ and computer models proposed to correct for defaulters. ' It is unlikely that the nine patients lost from the present study did undergo operation elsewhere, and they may be continuing with some form of $\mathrm{H}_{2}$ receptor antagonist therapy, as no unoperated patient in this 10 year study has had a sustained drug free remission. At the five year review, ${ }^{2} 18$ of the 30 patients taking cimetidine did so intermittently, while the remaining 12 patients used the drug continuously. By the time of the 10 year review, however, there had been a swing away from intermittent therapy, indicating the need for the majority of patients to take the drug continuously to maintain a satisfactory symptom free state.

Thus, long term maintenance appears to be a safe alternative to elective ulcer surgery for all but the most severe ulcer diathesis. The absence of significant side effects and the convenience of night time dosage make it acceptable to most patients. In this study $64 \%$ of those patients originally accepted for operation have avoided surgery. The saving in bed usage and theatre time for those patients has important revenue implications in terms of health care provision.

Finally, the failure of any patient in this study after 10 years of therapy to achieve lasting remission without the necessity for either surgery or continued drug therapy suggests that cimetidine has not altered the natural history of the duodenal ulcer diathesis.

\section{References}

1 Gray GR, Smith IS, MacKenzie I, Gillespie G. Long term cimetidine in the management of severe duodenal ulcer dyspepsia. Gastroenterology 1978; 74: 397-400.

2 Gray GR, Smith IS, McWhinnie D, Gillespie G. Fiveyear study of cimetidine or surgery for severe duodenal ulcer dyspepsia. Lancet 1982; i: 787-8.

3 Bardhan KD. Non-responders to cimetidine treatment. In: Baron $\mathrm{JH}$, ed. Cimetidine in the 80s. Edinburgh: Churchill Livingstone, 1981: 42-57.

4 Primrose JN, Axon ATR, Johnston D. Highly selective vagotomy and duodenal ulcers that fail to respond to $\mathrm{H}_{2}$ receptor antagonists. $\mathrm{Br}$ Med J 1988; 296: 1031-6.

5 Wade AG, Rowley-Jones D. Long term management of duodenal ulcer in general practice: How best to use cimetidine? Br Med J 1988; 296: 971-3.

6 Bardhan KD. For the Anglo-Irish cimetidine long-term study group. Aliment Pharmacol Ther 1988; 2: 395405.

7 Underwood DD, Amos JC, Venables CW, et al. Three computer models for the calculation of peptic ulcer disease during long-term treatment. Aliment Pharmacol Ther 1988; 2: 407-18. 